\title{
DESIGNING PLASTER MORTAR FOR A HIGH-RISE BUILDING
}

\author{
Zeljko KOS, Valentyn PARUTA, Olga GNYP, Leonid LAVRENYUK, Iryna GRYNYOVA
}

\begin{abstract}
The article rethinks the approach to the development of compositions of plaster mortar as the load on the plaster coating located on the 1st or 24th floor of the building differs significantly. To solve the problem within the framework of existing concepts, principles and regulatory requirements are not possible, as they are applicable to the solutions used in low-rise building. To achieve this goal, it is necessary to develop the scientific basis for the design of plaster mortar. In order to do that, it is necessary to analyze the processes occurring in the plaster coating when it is applied and hardened, the knowledge of the mechanism of the destruction of the "masonry - plaster coating" system, and the calculation and evaluation of stresses. The designated physical and mechanical parameters and the selected plaster mortar compositions should ensure the "work" of the system at the maximum level of such stresses.
\end{abstract}

Keywords: calculation of stresses; high-rise building; mechanical parameters; physical parameters; plaster mortar

\section{INTRODUCTION}

An increase in the share of high-rise buildings, together with the widespread use of new wall materials, requires a rethinking of the approach to the design of plaster mortar compositions. This is due to the fact that the impacts and loads on the plaster coating located on the $24^{\text {th }}$ floor of a building are significantly different from those on the $1^{\text {st }}, 2^{\text {nd }}$ and $3^{\text {rd }}$ floor (Fig. 1).

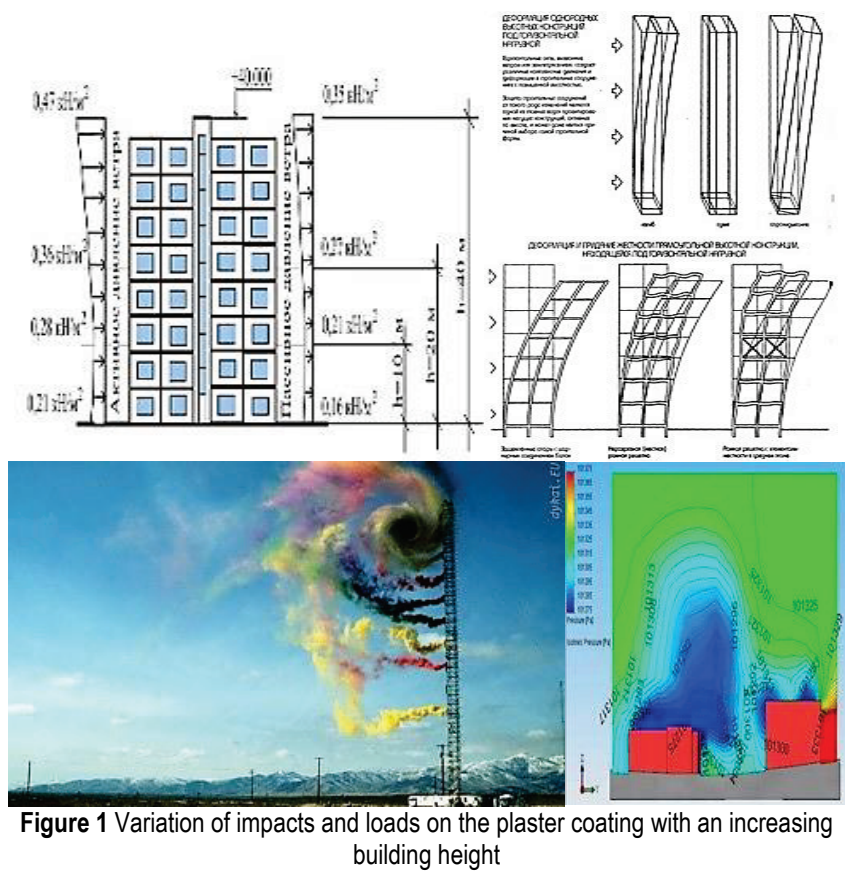

It is also necessary to take into account that when building high-rise buildings on the territory of the Ukraine, the average density of autoclaved aerated concrete is mainly $150-600 \mathrm{~kg} / \mathrm{m}^{3}$. Its properties (compressive strength, modulus of elasticity, temperature deformation) depend on the average density and significantly differ from the properties of traditional materials from which the walls are built (ceramic and silicate bricks, blocks of lightweight concrete and rocks).

In order to prevent the destruction of plaster coating, it is necessary to calculate the values of its physical-mechanical characteristics (compressive and bending strength, elastic modulus, etc.), taking into account the stresses in it and the contact zone with the cladding that arises when the solution is hardened and the wall structure is deformed. In this case, the maximum permissible strain should be less than destructive. Selecting the composition of the solution needs to be carried out by taking into account the processes occurring during the application and hardening of the mortar to the masonry. It is necessary to increase the water-retaining capacity of the mixture, to reduce the shrinkage of plaster coating during hardening, to reduce the number of cracks that occur during hardening and to prevent or slow down their development.

Normative requirements for plaster mortars for autoclaved aerated concrete walls are also not taken into account as they are contradictory and, in our opinion, not substantiated. For example, compressive strength should be 1,5-7,5 $\mathrm{MPa}$ (Russia), 2,5 $\mathrm{MPa}$ (Ukraine) and $10 \mathrm{MPa}$ (Germany). The flexural strength should be 1-1,25 $\mathrm{MPa}$ (Ukraine) and $2 \mathrm{MPa}$ (Russia). The value of adhesion to aerated concrete laying should be 0,15-3 MPa (Russia) and $0,5 \mathrm{MPa}$ (Ukraine). The design principles of plaster mortar compositions proposed by the authors are new directions in the building materials' science [1].

The aim of the research was to obtain plaster mortar with high crack resistance, while ensuring the requirements of normative documents for medium density, compressive strength and bending, and other parameters.

To achieve the required goals, the development of new scientific bases for the design of plaster mortar compositions is required. It is necessary to analyze the processes occurring in the plaster coating when it is applied and hardened, to know the destruction mechanism of the "masonry - plaster coating" system calculation and calculation of stresses.

Recent works dealing with the subject matter indicate that the durability of the wall structure depends to a large 
extent on the number of defects in the plaster coating and the contact area between it and the masonry $[2,8,9]$. The destruction of the "masonry - plaster coating" system is due to the accumulation and development of micro- and macrocracks in its structure. To assess the resource of such a system, it is necessary to determine the internal and external factors, the degree of their impact, the calculation of the stress state, knowledge of the processes of nucleation, accumulation of damages and growth of macrocracks. The assigned physical and mechanical parameters and compositions of plaster mortar should ensure the "work" of the system at the maximum level of such stresses.

\section{ANALYSIS OF THE PROCESSES OCCURRING IN PLASTER MORTAR}

Masonry made of autoclaved aerated concrete has a high capillary potential due to considerable pore volume $(520$ $\left.\mathrm{mm}^{3} / \mathrm{g}\right)$ and their high specific surface area $\left(22-34 \mathrm{~m}^{2} / \mathrm{g}\right)$ [2]. After the mortar is applied to masonry, because of its low water-retaining capacity, liquid is sucked out from the lyophilic pores and capillaries of the masonry material (Fig. $2 \mathrm{a})$. The pore filling rate $(v)$ is determined by the Poiseuille equation:

$v=-\frac{r^{2}}{8 \eta} \frac{\Delta p}{l}$

where: $l$ - is the length of the area of the absorbed liquid, $\eta$ is its viscosity, $\Delta p$ - the pressure drop across section 1 is equal to the capillary pressure of the meniscus:

$\Delta p=-2 s_{12} \cos \frac{q}{r}$

Therefore, the dissolution of cement and the formation of a supersaturated solution occur with reduced water content. Because of this, the incomplete hydration of cement occurs and non-equilibrium, metastable neoplasms of the following type are formed:

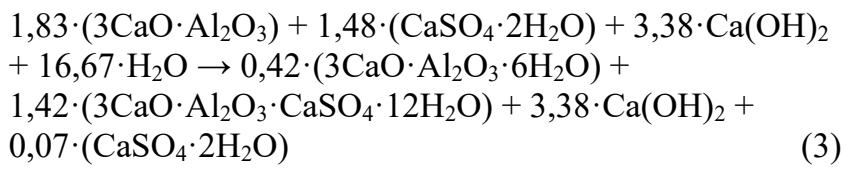

The loss of water leads to the shrinkage of the plaster mortar $-2,5-5,8 \mathrm{~mm} / \mathrm{m}$ [3]. Since the aerated concrete masonry "holds back" these deformations, this leads to stresses in it $(\delta)$, which are seven times higher than its tensile strength:

$\delta=\frac{\Delta \varepsilon^{*} \cdot E}{1-\mu}$,

where: $E$ and $\mu$ are the modulus of elasticity and the Poisson's ratio of the plaster coating; $\Delta \varepsilon^{*}$ - the difference of deformations of plaster and aerated concrete base [6].

Because of these stresses and the fact that a decrease in the degree of hydration of the cement has led to a decrease in the ultimate extensibility of the material (by $20-50 \%$ ) [7, 9 , 10], cracks develop in the plaster coating (on the surface and in the volume of the material), as well as in the contact area between the ceiling and masonry (Fig. 2c, 2d, 2e).

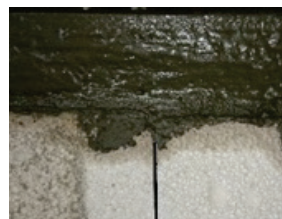

a)

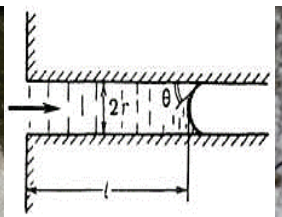

b)

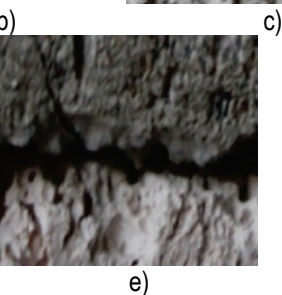

c)

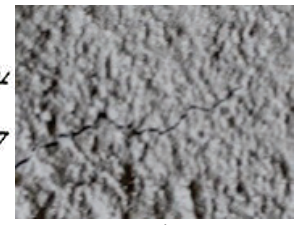

d)

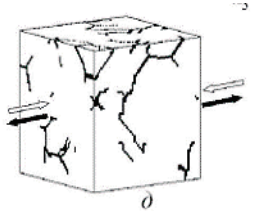

Figure 2 Low water retention solution on the masonry material (a), cracking in the plaster coating and the contact area between the ceiling and masonry $(c, d, e)$

During operation, they "develop" and are combined into trunk lines. The causes of cracks are temperature and humidity, deformation of plaster and masonry $[4,5]$ and the difference between them (Fig. 3c, 3d), the strain caused by them (Fig. 3a), moisture, ice, and corrosive materials.

Cyclic temperature-humidity effects lead to deformation $\left(\Delta L_{p}, \Delta L_{c}, \Delta L_{\mathrm{TB}}\right)$ and additional stresses in the plaster coating $(\delta)$, which are the cause of the development of a whole family of main cracks.

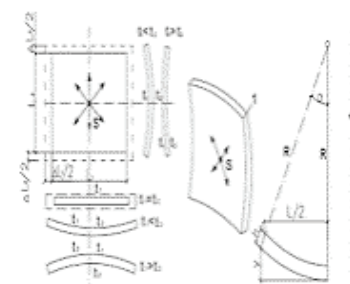

a)

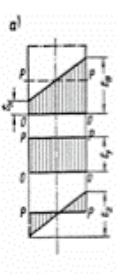

b)

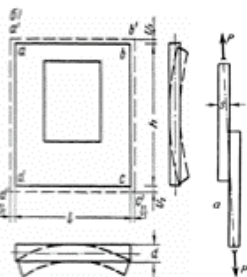

b)

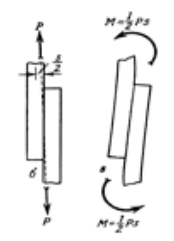

c)

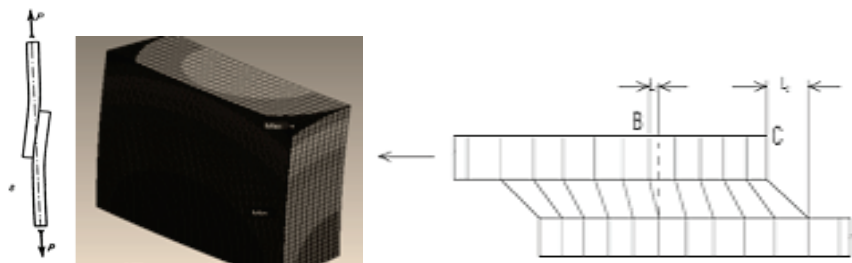

e)

Figure 3 Temperature and humidity deformation of the masonry $(a, b)$ and the stresses in it (d)

$\Delta L_{p}=\alpha \cdot \Delta T_{p} \cdot L$

(5)
$\Delta L_{c}=\alpha \cdot \Delta T_{c} \cdot L$, 
$\Delta L_{\mathrm{TB}}=\left(\alpha \cdot \Delta L \cdot T \cdot F_{\mathrm{m}}\right)+\left(\Delta L_{q} \cdot L\right)$,

where: $\Delta L_{p}, \Delta L_{c}$ - deformation of tension and compression; $\alpha$ - coefficient of temperature elongation of the material; $\Delta T_{p}$, $\Delta T_{c}$ - the temperature difference; $L$ - the length of the wall element; ${ }_{\Delta} L_{\mathrm{TB}}$ - heat and humidity deformation; $F_{\mathrm{m}}$ - an indicator of material defects; $\Delta L_{q}$ - humidity deformations [4].

$$
\begin{aligned}
& \delta=\kappa \cdot \sqrt{\left[\alpha_{t}+b(L-c)\right] \delta^{*}}, \\
& \delta^{*}=E \cdot \alpha_{t} \cdot \Delta t,
\end{aligned}
$$

where: $E$ - modulus of elasticity; $\alpha_{t}$ - coefficient of linear expansion of plaster coating; $\Delta t$ - calculated temperature drop.

Masonry and plaster coating have different magnitudes of thermal deformations. The magnitude of these deformations is determined from the expression [6]:

$$
\begin{aligned}
& \Delta L=L_{0} \cdot \alpha_{t} \cdot \Delta t, \\
& \Delta t=t_{2}-t_{1},
\end{aligned}
$$

where: $\Delta L$ - the elongation or contraction of the wall structure is relative; $L_{0}$ the length of the wall structure at the time of construction; $\alpha_{t}$ - coefficient of thermal expansion and autoclaved aerated plaster coating $[2,6], \Delta t$ - changing the temperature of the wall structure; $t_{1}$ - environmental temperature at the time of construction of gas concrete masonry and applying stucco coatings; $t_{2}$ - the maximum and minimum temperature, which affect the wall structure in the summer and winter periods;

With temperatures as low as $-20{ }^{\circ} \mathrm{C}$, the total compression deformation of an $8 \mathrm{~m}$ long wall, produced in summer at a temperature of $+30{ }^{\circ} \mathrm{C}$, with a coefficient of temperature expansion of aerated concrete laying of $8 \times 10^{-6}$ grad- 1 and a temperature change from +30 to $-20^{\circ} \mathrm{C}, e=50$ ${ }^{\circ} \mathrm{C}$ is $3.2 \mathrm{~mm}$. In the summer, when heated to $+80^{\circ} \mathrm{C}$ [2], the expansion deformation is $3,2 \mathrm{~mm}$.

In the winter, the compression deformation of the plaster mortar (1:4) will be $0,55 \mathrm{~mm} / \mathrm{m}$, and the total compression deformation of the plaster coating for the $8 \mathrm{~m}$ long wall will be $4,4 \mathrm{~mm}$. In the summer, the total deformation expansion of the plaster coating will be $4,4 \mathrm{~mm}$. Deformations of expansion and contraction cause tension $(\sigma)$ in the masonry and the plaster covering which can be determined by converting the equation:

$$
\Delta L: L_{0}=\sigma: E,
$$

where: $\Delta L$ - the elongation or contraction of the wall structure; $L_{0}$ - length of the wall structure at the time of erection; $\sigma$-stresses in $\mathrm{N} / \mathrm{mm}^{2} ; E$ - the modulus of elasticity in $\mathrm{N} / \mathrm{mm}^{2}$ [5].

The difference between the deformations, the elasticity modules of the masonry and the plaster coating is the reason for the shear strains in the "masonry - plaster coating" contact zone (Figs. 3e, 4a) and stresses $(\tau)$ (Fig. 4b), which predetermine the development of a crack in the contact zone:

$$
\tau=\frac{\Delta T_{1} \cdot \alpha_{1}-\Delta T_{2} \cdot \alpha_{2}}{\left(\frac{1}{E_{1}}+\frac{1}{E_{2}}\right)},
$$

where: $\tau$ - shear stress from temperature deformations, $\mathrm{kgf} / \mathrm{cm}^{2} ; \Delta T_{1}, \Delta T_{2}$ - the temperature difference at the time of installation and operation of the plaster coating and masonry, ${ }^{\circ} \mathrm{C} ; \alpha_{1}, \alpha_{2}$ - coefficient of thermal expansion of masonry and plaster coating; , - moduli of elasticity of masonry and plaster coating, $\mathrm{kgf} / \mathrm{cm}^{2}$.

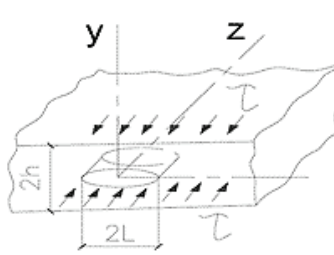

a)

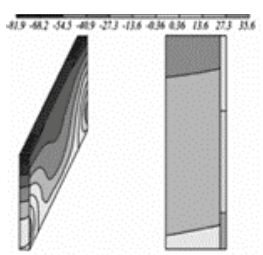

b)

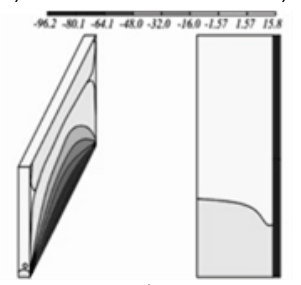

c)

Figure 4 Deformations (a), stresses isopole from PC LIRA in the contact zone between the plaster coating and the masonry (b), (c)

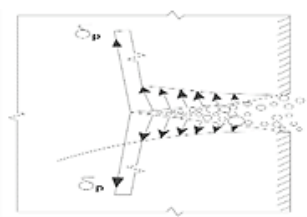

a)

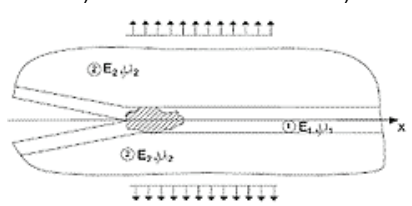

c)

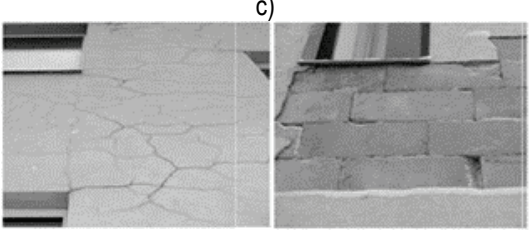

d)

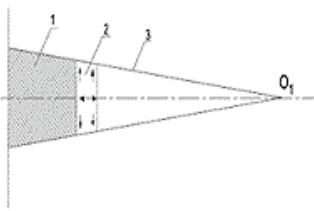

b)

e)
Figure 5 Development of the main crack in the contact zone due to the action of water $(a)$, ice $(b, c)$, and destruction of the plaster coating $(d, e)$

Atmospheric moisture, penetrating into the cracks of plaster coating, and through them into the contact zone, creates a wedging pressure at the top of the crack. Due to this, tensile stresses appear in this zone (Fig. 5a), which leads to a 
further development of cracks in the plaster coating in its contact zone with the masonry.

At temperatures below zero degrees Celsius, the development of cracks is accelerated due to the transformation of water into ice (Figs. 5b, 5c), which ultimately leads to the destruction of the plaster coating and the wall structure (Fig. 5d, 5e).

\section{EXPERIMENTAL STUDY OF PLASTER MORTAR}

Reducing the elastic modulus of the stucco mortar and increasing its deformability are used in the case of fine aggregate with a low elastic modulus. In the experiment, to reduce the shrinkage of plaster coating and prevent the appearance of shrinkage cracks, a small filler and a filler with a low modulus of elasticity (vermiculite and from aerocrete fights (mix No. 1), limestone stone waste and pearlite waste (No. 2 mix) were used.

The optimization of prescription and technological factors was carried out using a five-factor plan (Tab.1). For the experiment, the main factors were determined: X1 Binder consumption (cement and lime mixture), X2 - Filler and aggregate consumption (perlite, carbonate and their mixture), X3 - Fiber consumption (diameter 18,7 $\mu \mathrm{m}$, length $12 \mathrm{~mm}$ ), X4 - redispersible polymer powder consumption Winnapas 5043 H, X5 - Consumption Tylose MBZ 15009. Their presence will also enable the reduction of the modulus of the elasticity of the plaster coating and the stress in it and the contact zone, and with the addition of a polymer fiber, the rate of development of cracks will be reduced, which will increase the durability of the coating and the wall structure.

The crack resistance of plaster mortars was determined in accordance with the National Standards of Ukraine (DSTU B B.2.7-126: 2011), while applying the mortar mixture to the aerated concrete foundation by using a frame device. A positive evaluation of crack resistance is no crack on the samples after curing for 24 hours under air-dry conditions. Since the crack resistance in the plaster mortar according to the National Standards of Ukraine (DSTU B B.2.7-126: 2011) are qualitative in nature, it was calculated that it is necessary to quantify the crack resistance coefficient $\left(C_{\text {cr }}\right)$ of the formula:

$C_{\mathrm{cr}}=\frac{R_{\mathrm{b}}}{R_{\mathrm{c}}}$

where: $R_{\mathrm{b}}$ - bending strength; $R_{\mathrm{c}}$ - compressive strength plaster.

To determine the crack resistance of the plaster coating, its deformations, crack formation, and fracture were simulated on expanding deformable masonry (expansion deformations). For this purpose, cylinder samples were formed from the studied compositions (outer diameter 240 $\mathrm{mm}$, inner diameter $200 \mathrm{~mm}$, wall thickness $20 \mathrm{~mm}$, height $150 \mathrm{~mm}$ ). Tensile deformations in plaster coating were made by using two conical installations (Fig. 6a-6c).
To determine the properties of plaster mortar, more than 500 samples of a $40 \times 40 \times 160 \mathrm{~mm}$ beam were made on a gasconcrete base.

To simulate the real conditions, plaster coating was left to air-dry, and after 28 days of hardening, compressive strength, bending strength and density were determined (Tab. 2 ). Fracture toughness was determined visually by the presence of cracks in the coating and by calculating the fracture toughness ratio as the ratio of the bending strength in relation to compressive strength.

The study used an experimental statistical model (ESM) developed by V. Voznesensky and T. Lyashenko [11]. Based on the data obtained in the experiment, adequate experimental statistical (ES) models were constructed which describe the influence of variable factors on the properties of stucco mortars. The calculation of the model and its geometric display were carried out in the COMPEX system. The result is plaster mortar with the following properties: Composition No. 1: average density $600-1500 \mathrm{~kg} / \mathrm{m}^{3}$, bending strength $12-18 \mathrm{~kg} / \mathrm{cm}^{2}$, compressive strength $18-36$ $\mathrm{kg} / \mathrm{cm}^{2}$, crack resistance coefficient 0,56-0,74 (Fig. 7a-d).
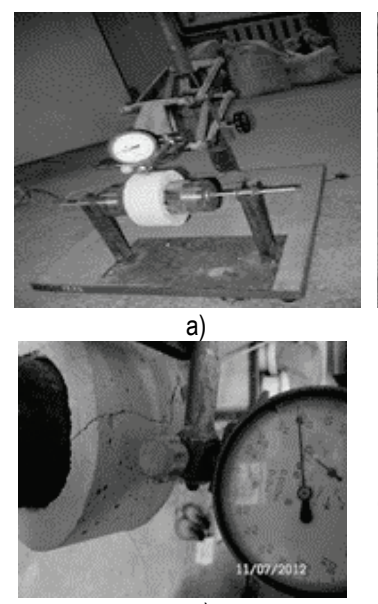

c)

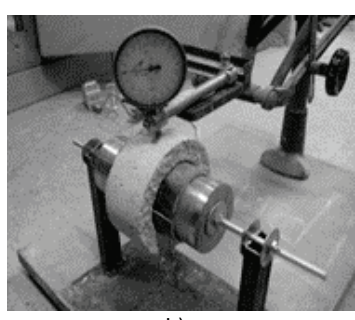

b)

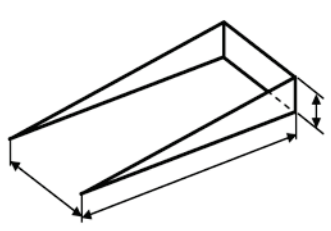

d)
Figure 6 Installation for determining crack resistance (a-c), the framework for determining the crack resistance of the solution (d)

\begin{tabular}{|c|c|c|c|c|c|c|}
\hline \multirow[t]{2}{*}{ 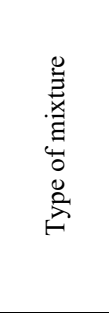 } & \multirow[t]{2}{*}{ 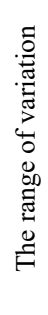 } & 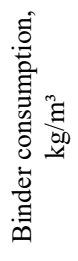 & 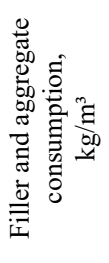 & 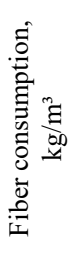 & 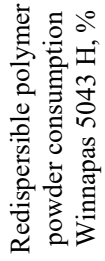 & 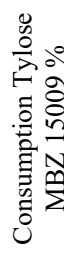 \\
\hline & & $\mathrm{X} 1$ & $\mathrm{X} 2$ & $\mathrm{X} 3$ & $\mathrm{X} 4$ & $\mathrm{X} 5$ \\
\hline \multirow{3}{*}{ Mix № 1} & 1 & 500 & $1,05 / 1$ & 1,2 & 5 & 0,5 \\
\hline & 0 & 400 & $1,05 / 1$ & 0,9 & 3 & 0,3 \\
\hline & -1 & 300 & $1,05 / 1$ & 0,6 & 1 & 0,1 \\
\hline \multirow{3}{*}{ Mix №2 } & 1 & 400 & $1,05 / 1$ & 1,2 & 5 & 0,5 \\
\hline & 0 & 300 & $1,05 / 1$ & 0,9 & 3 & 0,3 \\
\hline & -1 & 200 & $1.05 / 1$ & 0,6 & 1 & 0,1 \\
\hline
\end{tabular}


Table 2 Physical-mechanical properties of the plaster mortar

\begin{tabular}{|c|c|c|c|c|c|}
\hline \multirow[b]{2}{*}{ № } & \multicolumn{5}{|c|}{ Mortar properties } \\
\hline & $\begin{array}{c}\text { Water } \\
\text { retention \% }\end{array}$ & $R_{\mathrm{b}}, \mathrm{kgf} / \mathrm{cm}^{2}$ & $\begin{array}{c}R_{\mathrm{c}} \\
\mathrm{kgf} / \mathrm{cm}^{2}\end{array}$ & $\begin{array}{c}W_{p}, \\
\mathrm{kgf} / \mathrm{cm}^{2}\end{array}$ & $\begin{array}{l}\text { Average } \\
\text { density, } \\
\mathrm{kg} / \mathrm{m}^{3}\end{array}$ \\
\hline 1 & 94 & 8 & 10 & 0.68 & 555 \\
\hline 2 & 97 & 16 & 18 & 0.74 & 711 \\
\hline 3 & 97 & 10 & 12 & 0.58 & 1486 \\
\hline 4 & 98 & 20 & 28 & 0.56 & 1512 \\
\hline 5 & 91 & 9 & 14 & 0.72 & 490 \\
\hline 6 & 93 & 16 & 21 & 0.78 & 723 \\
\hline 7 & 99 & 15 & 20 & 0.4 & 1617 \\
\hline 8 & 98 & 17 & 21 & 0.64 & 1496 \\
\hline 9 & 98 & 13 & 14 & 0.76 & 510 \\
\hline 10 & 96 & 20 & 27 & 0.24 & 703 \\
\hline 11 & 97 & 24 & 38 & 0.38 & 1611 \\
\hline 12 & 98 & 26 & 30 & 0.24 & 1568 \\
\hline 13 & 95 & 14 & 16 & 0.66 & 570 \\
\hline 14 & 94 & 22 & 24 & 0.68 & 678 \\
\hline 15 & 97 & 25 & 44 & 0.58 & 1592 \\
\hline 16 & 95 & 38 & 65 & 0.38 & 1619 \\
\hline 17 & 97 & 17 & 20 & 0.48 & 1109 \\
\hline 18 & 96 & 26 & 36 & 0.72 & 1166 \\
\hline 19 & 98 & 15 & 20 & 0.74 & 623 \\
\hline 20 & 94 & 21 & 34 & 0.4 & 1525 \\
\hline 21 & 95 & 23 & 38 & 0.56 & 1284 \\
\hline 22 & 95 & 19 & 22 & 0.6 & 1305 \\
\hline 23 & 97 & 16 & 19 & 0.74 & 1072 \\
\hline 24 & 97 & 20 & 27 & 0.62 & 1113 \\
\hline 25 & 97 & 18 & 23 & 0.28 & 1111 \\
\hline 26 & 99 & 15 & 20 & 0.58 & 1094 \\
\hline 27 & 95 & 16 & 18 & 0.6 & 1078 \\
\hline
\end{tabular}

Where: Water retention capacity - the water retention capacity of a mortar mixture, $R_{\mathrm{b}}$ - bending strength of hardened mortar, $R_{\text {c.- }}$ compressive strength of hardened mortar, $W_{p}$ - water absorption by weight in 24 hours, $\mathrm{kg} / \mathrm{m}^{2}$ of hardened mortar.

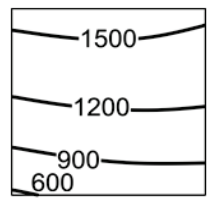

a

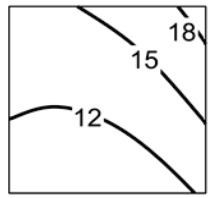

b

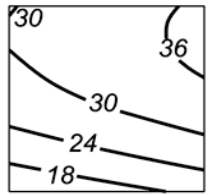

c

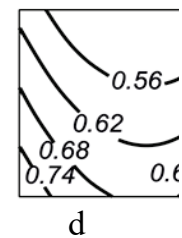

d
Figure 7 Isopole of basic physical and mechanical properties of the physicalmechanical properties of plaster mortar: average density (a), flexural strength (b) and compression (c), crack resistance (d) composition No. 1

Composition No. 2: average density $700-1100 \mathrm{~kg} / \mathrm{m}^{3}$, bending strength $10-25 \mathrm{~kg} / \mathrm{cm}^{2}$, compressive strength $15-35$ $\mathrm{kg} / \mathrm{cm}^{2}$, crack resistance coefficient 0,25-1 (Fig. 8a-8d).

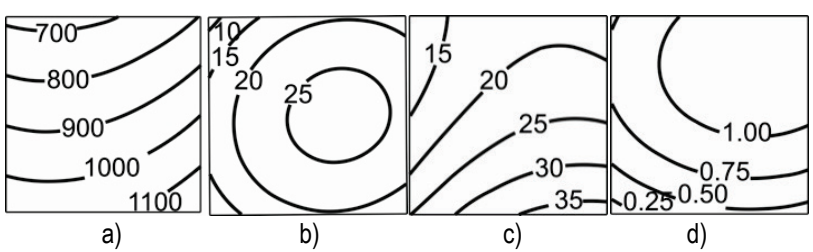

Figure 8 Isopole of basic physical and mechanical properties of the physicalmechanical properties of plaster mortar: average density (a), flexural strength (b), compressive strength (c), crack resistance coefficient (d) composition No. 2

The obtained plaster mortar meets the requirements of normative documents for the medium density (600-1600 $\left.\mathrm{kg} / \mathrm{m}^{3}\right)$, flexural strength $(0,98-2,45 \mathrm{MPa})$ and compression $\left(25-50 \mathrm{~kg} / \mathrm{cm}^{2}\right)$. The plaster coating has high crack resistance, the crack resistance coefficient is $0,25-1$, while the cracking resistance is considered for the plaster with an index $>0,26$.

\section{CONCLUSIONS}

An increase in the share of high-rise buildings and the widespread use of new wall materials requires the development of scientific methods for the design of plaster mortar compositions. For this analysis, processes occurring in the plasters during their application and hardening were analyzed, failure mechanism for "bricklaying - plaster coating" systems were considered, and formula for calculating stress is given. The principles and criteria under which the durability of the plaster coating and the wall structure will be provided were formulated, the constituents were selected and the composition of the material was selected.

\section{REFERENCES}

[1] Paruta, V. (2012). Theoretical premises for optimizing the formulation and technological parameters of plaster mortars for walls made of aerated concrete blocks. Civil Engineering Journal, 30-36. https://doi.org/10.5862/MCE.34.4

[2] Galkin, S. (2006). Application of cellular concrete products. Theory and practice, NP Strinko LLC.

[3] Knat'ko, M. (2008). On the Question of Durability and Energy Efficiency of Modern Enclosing Wall Structures of Residential, Administrative, and Industrial Buildings. Engineering and Construction Journal, 50-53.

[4] Voldrich, F. (1978). Deformation joints in the construction of above-ground buildings, Stroyizdat.

[5] Emelyanov, A. (1964). Damage to the exterior panels of residential prefabricated buildings with temperature deformations according to field studies. Analysis of the causes of accidents and damage to building structures, 153-177.

[6] Blazi, V. (2005). Reference Designer. Construction Physics.

[7] Rusova, R. (2001). Basis of wall and finishing materials production.

[8] Sazhneva, N. (2009). Protective systems for the finishing of cellular concrete of low density. Building materials, 17-19.

[9] Paplavskis, J. (2010). Requirements for plaster for exterior wall finishing of cellular concrete. Problems of the operational reliability of exterior walls based on autoclaved aerated concrete blocks and the possibility of their protection against moisture. Plaster compositions for exterior decoration of aerated concrete walls: workshop materials, 10-15.

[10] Yemelyanov, A. (1964). Damage to the exterior panels of residential prefabricated buildings during thermal deformations according to field studies. Analysis of the causes of accidents and damage to building structures, 153-177.

[11] Voznesensky, V. \& Lyashenko, T. (1989). Numerical methods for solving construction and technological problems on a computer. 
Authors' contacts:

Zeljko KOS, PhD, Ass. Prof.

University North, University Centre of Varaždin,

104. brigade 3, 42000 Varazdin, Croatia

+38598757989; zeljko.kos@unin.hr

Valentyn PARUTA, PhD, Ass. Prof.

Odessa State Academy of Civil Engineering and Architecture,

4, Didrikhson str., Odesa, Ukraine

+380676358991, docent2155@gmail.com

Olga GNYP, PhD, Ass. Prof.

Odessa State Academy of Civil Engineering and Architecture,

4, Didrikhson str., Odesa, Ukraine

+380679157473, asp@ogasa.org.ua

Leonid LAVRENYUK, PhD, Ass. Prof.

Odessa State Academy of Civil Engineering and Architecture,

4, Didrikhson str., Odesa, Ukraine

leonid-2319@ukr.net

Iryna GRYNYOVA, PhD

Odessa State Academy of Civil Engineering and Architecture,

4, Didrikhson str., Odesa, Ukraine

+380939799301, irene.grinyova@gmail.com 